\title{
PEWARISAN BUDAYA DALAM KESENIAN BRINGBRUNG DI KELURAHAN LEDENG, KECAMATAN CIDADAP HILIR, KOTA BANDUNG
}

\section{CULTURAL HERITAGE IN BRINGBRUNG ART IN LEDENG SUB-DISTRICT OF CIDADAP HILIR, $B A N D U N G$}

\author{
Ricky Nugraha Oktovan, Dede Suryamah, Sriati Dwiatmini \\ nugraharicky2@gmail.com \\ Program Studi Antropologi Budaya, Fakultas Budaya dan Media \\ Institut Seni Budaya Indonesia Bandung
}

Artikel diterima: 22 Oktober 2020 || Artikel direvisi: 9 November 2020 || Artikel disetujui: 13 November 2020

\begin{abstract}
ABSTRAK
Skripsi ini adalah hasil penelitian Antropologi budaya mengenai pewarisan budaya dalam kesenian, yaitu kesenian Bringbrung di Kelurahan Ledeng, Kecamatan Cidadap Hilir, Kota Bandung. Penelitian berjudul "Pewarisan Budaya dalam kesenian Bringbrung di Kelurahan Ledeng, Kecamatan Cidadap Hilir, Kota Bandung", pembahasannya menggunakan pendekatan kualitatif dengan metode deskriptif analitik. Teori yang digunakan adalah teori sosial dan budaya yang mengungkap pewarisan budaya secara sosialisasi, enkulturasi dan internaslisasi. Penelitian ini, bertujuan untuk menjelaskan sistem sosial dalam pewarisan budaya kesenian Bringbrung di Kelurahan Ledeng Kecamatan Cidadap Hilir, Kota Bandung.

Hasil penelitian ini adalah mengungkap tentang: 1) Proses pewarisan dalam Kesenian Bringbrung dilakukan secara Sosialisasi, Enkulturasi dan Internalisasi; 2) Media pewarisan meliputi praktek menabuh terebang, menyayikan lagu-lagu, menari dan pengelolaan keorganisasian; 3) Faktor pendukung dalam pewarisan adalah masyarakat, orang-tua, pemerintah, media sosial, seniman dan sanggar seni Bringbrung; sedangkan faktor penghambat meliputi keterbatasan mengenal budaya leluhur, profit seni Bringbrung tidak menjamin kehidupan, dan derasnya globalisasi yang memarjinalkan seni tradisional.

Pewarisan budaya yang dilakukan oleh seniman Bringbrung kepada generasi-generasi penerus bertujuan agar kesenian Bringbrung dapat dilestarikan keberadaannya.
\end{abstract}

Kata Kunci: Bringbrung, Pewarisan Budaya, Kelurahan Ledeng

\section{ABSTRACT}

This thesis is the result of cultural anthropology research on cultural inheritance in art, namely Bringbrung art in Ledeng sub-district, Cidadap Hilir, Bandung.The research with the title 'Cultural Heritage in Bringbrung art in Ledeng sub-district of Cidadap Hilir, Bandung', discussion uses a qualitative approach with descriptive analytic methods. The theory that is used in this research is a social and cultural theory that reveals cultural inheritance through socialization, enculturation, and internalization. This study aims to explain the social system in the cultural inheritance of Bringbrung art in Ledeng sub-district, Cidadap Hilir, Bandung.

The results of this study are revealing about: 1) The process of inheritance in Bringbrung Art is carried out in socialization, enculturation and internalization; 2) Media of inheritance includes the practice of beating beats, singing songs, dancing and organizational management; 3) The supporting factors in inheritance are the community, parents, government, social media, artists and Bringbrung art studios: while inhibiting factors include limitations on knowing the ancestral culture, Bringbrung's art profit does not guarantee life, the rapid globalization that marginalizes traditional art.

The cultural heritage carried out by Bringbrung artists to future generations aims to preserve the existence of Bringbrung art.

Keywords: Bringbrung, Cultural Heritage, Ledeng Village 


\section{PENDAHULUAN}

\section{A. Latar Belakang}

Kesenian tradisional Bringbrung adalah salah satu kesenian tradisi Sunda yang ada di Kota Bandung, tepatnya di Kelurahan Ledeng, Kecamatan Cidadap Hilir, Kota Bandung. Secara umum kesenian Bringbrung erat kaitannya dengan seni ritual, hal ini tampak pada sajian nyanyian yang diperdengarkan adalah puji-pujian kepada Tuhan. Dalam penyajiannya, seni ini digunakan untuk peristiwa-peristiwa syukuran panen, syukuran lahir anak, syukuran sunatan dan maulid nabi, bahkan juga sering digunakan untuk media dakwah.

Kesenian Bringbrung dalam melantunkan lagu-lagu bernuansa religi, menggunakan literasi yang diambil dari kitab Barzanji. Dalam pelaksanaannya, dipertunjukkan juga sarana dan prasarana ritual seperti ngukus, sesaji dan bunga rampe. Kehadiran unsurunsur mitis dari sarana dan prasarana ritual, dalam penyajian seni Bringbrung, kadang kala memunculkan adanya orang kesurupan, fenomena tersebut menunjukkan bahwa kesenian Bringbrung masih memiliki situasi dan kondisi magis dalam penyajiannya. Apa yang menjadikan seni ini bernuansa magis. Dalam penelitian Made (2016), disebutkan bahwa suasana magis dalam seni Bringbrung disebabkan oleh adanya komposisi nada-nada dalam Bringbrung yang memiliki karakteristik wingit ${ }^{1}$ sehingga mampu mendatangkan rohroh yang masuk ke tubuh orang dan menyebabkan trance (kesurupan).

Keberadaan dan kehidupan seni tradisional Bringbrung ibarat hidup segan mati pun segan. Kendati, kesenian Bringbrung masih eksis di masyarakat, hal ini nampak dari masih digelarkannya kesenian ini pada peristiwaperistiwa tertentu seperti syukuran dan pertunjukkan pada perayaan maulid Nabi dan Isra Mi'raj, akan tetapi dalam perkembangannya, menurut Pak Dannis (pimpinan seni Bringbrung), kesenian Bringbrung masa kini dapat dikatakan sudah jarang dipertunjukan untuk peristiwa syukuran panen dan kelahiran (wawancara dengan Bapak Dannis, tanggal 6 September 2019).

Saat diwawancara, Pak Dannis

\footnotetext{
${ }^{1}$ Wingit adalah adjektiva (kata sifat) yang berarti angker.
}

menyatakan bahwa beliau sangat berharap seni Bringbrung dapat dilestarikan, tapi melihat realita yang ada, seni Bringbrung memang kurang banyak peminat terutama generasi mudanya. Faktor yang membuat para generasi penerus kurang tertarik untuk melestarikan pentas kesenian Bringbrung, menurut penulis antara lain: pertama, tidak mengenal budaya leluhur; kedua, seni Bringbrung tampak tidak memberikan profit bagi kehidupan; ketiga, derasnya pengaruh globalisasi dalam dunia seni sehingga lebih menyukai seni modern. Ketidaktertarikan generasi muda ini, diprediksi menjadi faktor seni Bringbrung tidak berkembang dan membuat kurang optimalnya regenerasi dalam kesenian Bringbrung yang mendukung pada keberlanjutan seni Bringbrung ini.

Sehubungan dengan itu, peneliti merasa tertarik untuk menelusuri masalahmasalah tersebut terutama masalah regenerasi kesenian Bringbrung kepada generasi selanjutnya. Menurut peneliti, masalah regenerasi sangat penting dalam eksistensi kesenian Bringbrung di wilayah tersebut, hal ini dipicu dengan melihat realita yang tampak, selain kurangnya jumlah grup seni Bringbrung yang ada, juga kondisi para pemainnya (senimannya) yang sudah tua. Fakta ini diungkapkan oleh Oyoh Komariah sebagai berikut:

"Kasenian Bringbrung lahir jeung mekar
di Kalurahan Ledeng Kacamatan Cidadap
Hilir Kota Bandung.Kasenian Bringbrung
terus ngalaman parobahan-parobahan nu
luyu kana parobahan jaman nu mawa
pangaruhkana lunturna seni tradisional ku
kamajemukan seni modern jeung pola pikir
masyarakat, hal ieu nu mere tanda yen
masyarakatna teu konsisten dina ngokola-
keun ieu kasenian nepika grup Bringbrung
tinggal nyesahiji."

Terjemahan:

Kesenian Bringbrung lahir dan mekar di Kelurahan Ledeng, Kecamatan Cidadap Hilir, Kota Bandung. Kesenian Bringbrung berada di dalam perubahan jaman yang membawa pengaruh terhadap lunturnya kesenian tradisional karena kemajemukan kesenian modern dan pola pikir masyarakatnya, hal ini memberi tanda bahwa 
Ricky, Dede, Sriati - Pewarisan Budaya dalam.....

masyarakat tidak konsisten dalam mengelola kesenian Bringbrung sehingga kesenian ini tinggal bersisa satu grup.

\section{B. Perumusan Masalah}

Penulis berdasar keterangan informan Oyoh Komariah tersebut menjadi latar-belakang keinginan mempelajari kesenian Bringbrung yang lahir dan berkembang di Kelurahan Ledeng, Kecamatan Cidadap Hilir Kota Bandung. Perubahan-perubahan yang merujuk pada perubahan zaman berdampak pada punahnya seni tradisional akibat kurang dapat berkompetisi dengan kemajemukan seni modern dan pola pikir masyarakat. Dalam situasi demikian, pewarisan tradisi kesenian Bringbrung menghadapi persoalan yang pelik. Tentu saja, hal ini menjadi objek studi yang menarik menjadi bahan penelitian.

Oleh sebab itulah, penulis merasa tertarik untuk menelusuri regenerasi dalam seni Bringbrung, karena melalui tata cara pewarisan budaya, sebuah kesenian bisa tetap eksis dalam masyarakatnya. Sehubungan dengan itu, perlu ditelusuri model pewarisan budaya yang bagaimana yang telah terjadi dalam kesenian Bringbrung; lalu proses pewarisan budaya seperti apa yang dilakukan oleh para seniman Bringbrung; media budaya apa saja yang telah diwariskan kepada kaum generasi muda di Kelurahan Ledeng terkait seni Bringbrung; serta faktor pendukung dan penghambat apa saja dalam pewarisan seni Bringbrung.

\section{METODA}

Penulis memakai metode penelitian kualitatif. Teknik pengumpulan data menggunakan studi literatur, observasi, dan wawancara. Peralatan penelitian alat dokumentasi dan alat rekam dengan perekam dan kamera maupun video yang terdapat dalam fasilitas teknologi yang terdapat dalam ponsel penulis. Sehubungan dengan objek penelitiannya fokus mempelajari pewarisan budaya dalam kesenian tradisional Bringbrung yang tinggal bersisa satu kelompok di Kelurahan Ledeng, Kecamatan Cidadap Hilir, Kota Bandung, Provinsi Jawa Barat.

\section{HASIL DAN PEMBAHASAN}

A. Kesenian Bringbrung di Kelurahan Ledeng

Untuk membahas kesenian Bringbrung, dalam bab ini akan diungkapkan instrumen seni Bringbrung, pola-pola tabuhannya, jenis-jenis lagunya, personal pemainnya, serta struktur pertunjukannya

\section{Instrumen Seni Bringbrung}

Instrumen seni Bringbrung adalah alatalat musik yang digunakan dalam kesenian Bringbrung. Pada saat ini, kesenian Bringbrung memiliki 7 instrumen yang terdiri dari terebang sebanyak enam (6) buah dan dog-dog kecil satu (1) buah. Terebang adalah sejenis alat musik tepuk yang menyerupai rebana yang konon sudah ada pada zaman HinduBudha, akan tetapi pada masa itu disebut sebagai Tabang-tabang yang istilah ini tertulis dalam kitab sastra zaman Kediri pada abad 12 yang ditafsirkan oleh beberapa ahli seperti H.H. Juynboll dan P.J Zoetmulder yaitu sebagai instrumen musik terebang pada masa sekarang (Sumardjo dkk, 2001: 139-140).

Umumnya, dalam kesenian tradisional, alat musik disebut waditra, ada beberapa macam jenis waditra, tergantung bentuk fisik instrumen yang digunakan, di antaranya, dengan cara ditiup, dipetik, ditepuk dan digesek. Waditra dalam seni Bringbrung termasuk pada instrumen yang dibunyikan secara ditepuk. Di Indonesia sendiri, model seni terebang mirip seperti halnya Bringbrung banyak tersebar senusantara, terutama di Pulau Jawa. Namanama kesenian tersebut antara lain, Rudat, Mawalan, Genjring, Tagoni dan sebagainya.

Secara etimologi, kesenian rudat merupakan salah satu jenis kesenian yang mana di dalamnya terdapat gerakan tari-tarian dengan iringan yang berbau terbangan. Jenis tarian dalam seni rudat ini sendiri mengandung gerakan-gerakan yang berbau beladiri dan juga terdapat seni suara di dalamnya. Kata rudat itu sendiri berasal dari bahasa Arab, yakni rudatun yang berarti "taman bunga“. Pada awalnya, kesenian rudatun ini sendiri tumbuh dan berkembang di lingkungan pesantren. Dalam kesenian rudat ini, kebisaan dari para santri tersebut dipadukan dengan kesenian yang didukung oleh masyarakat sekitar yakni kesenian Sunda. Dengan demikian, seni rudat 
ini merupakan salah satu jenis seni yang mengandung berbagai unsur, yakni seperti dakwah agama Islam, dan juga hiburan berupa kesenian tradisional setempat dan lebih dominan ke kesenian Sunda atau juga dalam bentuk tarian pencak silat.

Mawalan adalah salah satu kesenian dari Banten yang bernuansakan Islam. Alatalat yang digunakan untuk kesenian mawalan adalah beberapa rebana. Kesenian ini dimainkan oleh pria dan wanita, biasanya antara 6-8 orang. Sebelum acara dimulai ayat-ayat suci Al-quran dikumadangkan terlebih dahulu. Kemudian sambil menabuh rebana orang orang menyanyi. Kesenian yang populer ini biasa dipertunjukan pada acara khitanan.

Genjring adalah salah satu jenis alat musik pukul yang terbuat dari kayu dan kulit, bentuknya mirip dengan rebana atau gembyung. Kesenian Genjring hanya tinggal satu- satunya berasal dari Desa Bayalangu Kidul, Kecamatan Gegesik, Kabupaten Cirebon. Berdiri sejak tahun 1965, kesenian tersebut biasa tampil di berbagai acara hajatan dan hari-hari besar.

Selain terebang, pada masa kepemimpinan Abah Ulis seni Bringbrung dilengkapi dengan instrumen dog-dog. Dog-dog menurut Ubun Kubarsah (1994: 7) adalah:

Waditra jenis alat pukul berkulit, yang dimainkan dengan cara dipukul dengan menggunakan alat bantu pemukul. Waditra ini mempunyai fungsi sebagai alat penyaji ritme, istilah Dog-dog merupakan peniruan dari bunyi yang berasal dari suara waditranya. Waditra Dog-dog jika dibunyikan terdengar "Dug" atau "Dog", terutama untuk bunyi Dog-dog yang besar.

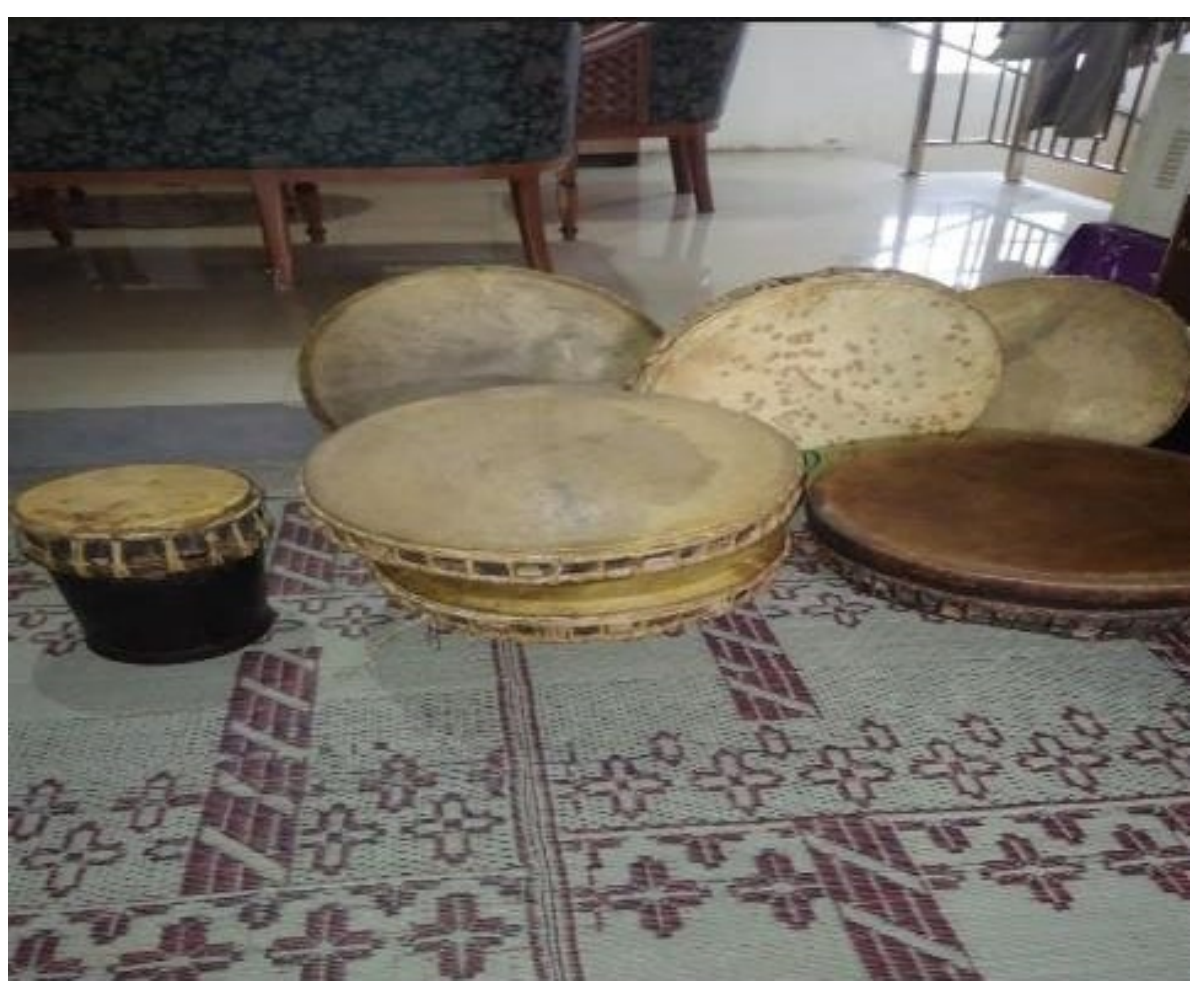

Gambar 1. Alat musik yang digunakan dalam kesenian Bringbrung.

(Sumber: Kubarsah, 1994)

Alat musik terebang yang digunakan pada kesenian Bringbrung meliputi beberapa bentuk instrumen terebang dalam berbagai ukuran sebagai berikut:

\begin{tabular}{|c|c|c|}
\hline NO & INSTRUMEN & \multicolumn{1}{c|}{ DESKRIPSI } \\
\hline 1 & Terebang 1 & $\begin{array}{l}\text { Alat musik Terebang yang memiliki diameter } 51 \mathrm{~cm} \text { dan } \\
\text { tinggi } 10 \mathrm{~cm}\end{array}$ \\
\hline
\end{tabular}


Ricky, Dede, Sriati - Pewarisan Budaya dalam.....

\begin{tabular}{|c|l|l|}
\hline 2 & Terebang 2 & $\begin{array}{l}\text { Alat musik Terebang yang memiliki diameter } 44 \mathrm{~cm} \text { dan } \\
\text { tinggi } 10 \mathrm{~cm}\end{array}$ \\
\hline 3 & Terebang 3 & $\begin{array}{l}\text { Alat musik Terebang yang memiliki diameter } 48 \mathrm{~cm} \text { dan } \\
\text { tinggi } 10 \mathrm{~cm}\end{array}$ \\
\hline 4 & Terebang 4 & $\begin{array}{l}\text { Alat musik Terebang yang memiliki diameter } 51 \mathrm{~cm} \text { dan } \\
\text { tinggi } 10 \mathrm{~cm}\end{array}$ \\
\hline 5 & Terebang 5 & $\begin{array}{l}\text { Alat musik Terebang yang memiliki diameter } 52 \mathrm{~cm} \text { dan } \\
\text { tinggi } 10 \mathrm{~cm}\end{array}$ \\
\hline 6 & Terebang 6 & $\begin{array}{l}\text { Alat musik Terebang yang memiliki diameter } 52 \mathrm{~cm} \text { dan } \\
\text { tinggi } 10 \mathrm{~cm}\end{array}$ \\
\hline 7 & Dog-dog & $\begin{array}{l}\text { Alat musik Terebang yang memiliki diameter } 21 \mathrm{~cm} \text { dan } \\
\text { tinggi } 30 \mathrm{~cm}\end{array}$ \\
\hline
\end{tabular}

Tabel 1. Deskripsi instrumen seni bringbrung.

\section{Pola tabuhan dalam seni Bringbrung}

Dalam kesenian Bringbrung, penyajian lagu dan iringannya dinamakan sekar gending. Kata sekar memiliki arti lagu, dan kata gending memiliki arti iringan. Hubungan antara lagu dan iringan harus harmoni (seimbang dalam irama), walaupun ada pula lagu yang disajikannya bebas irama saat diakhir lagu, namun hal tersebut hanya sebagian kecil saja, biasanya hanya improvisasi dari para pemain seni Bringbrung. Karena instrumen yang digunakan termasuk instrumen pukul, maka pola tabuhan yang dibangun adalah pola-pola komposisi ritmik.

Pola tabuhan instrumen seni Bringbrung menggunakan pola bentuk yang berbeda sesuai dengan kebutuhan sajian lagu. Berikut ini adalah pola-pola tabuhan yang disajikan oleh instrumen seni Bringbrung.

\section{POLA TABUHAN INSTRUMEN SENI BRINGBRUNG}

Motif 1

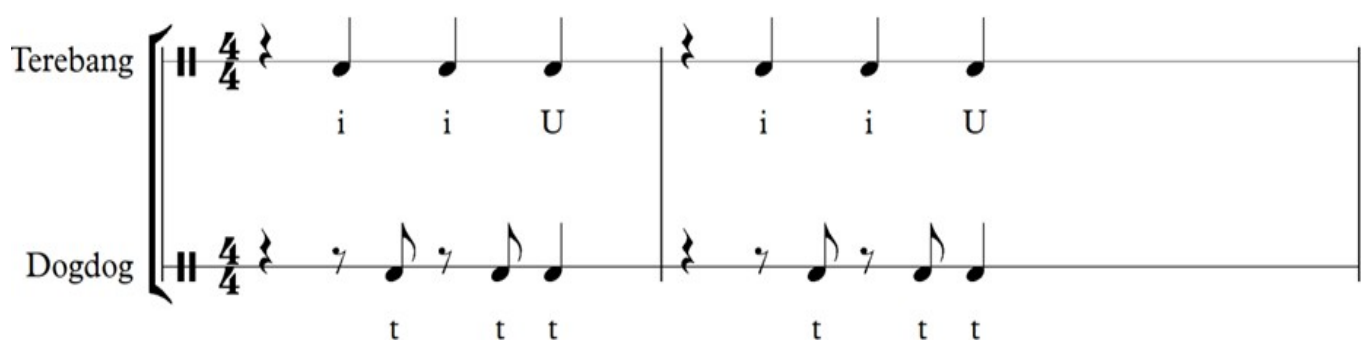

Motif 2

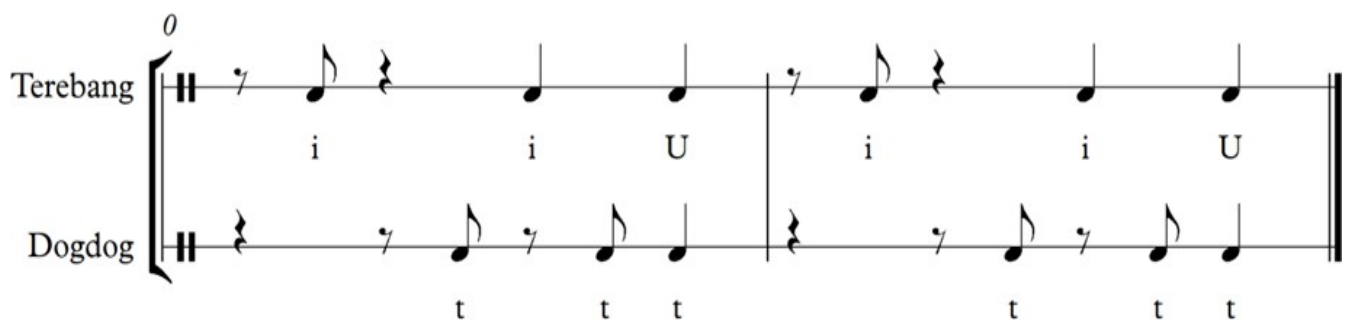


i

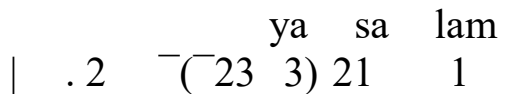

a la e

ka

Ya

13

$$
3
$$

bi

ya

$4 \quad 43$

.3

e

ek ala
$3 \mid$.

212 $\mathrm{mu}$

12

e

$\mathrm{Na}$

512

lek

2

a lek

(Sumber: Tesis Made Permadi tahun 2016)

\section{c. Partisipan} seniman, panitia dan partisipan.

\section{a. Seniman}

Seniman seni Bringbrung adalah para pemain musik (terebang dan dog-dog) serta penari. Akan tetapi, personal penari biasanya adalah partisipan dalam kesenian Bringbrung. Dalam hal ini, seni Bringbrung tidak memiliki grup penari khusus kesenian ini.

\section{b. Panitia}

Untuk pertunjukan peristiwa besar di masyarakat (muludan dan isra mi'raj), para panitia adalah warga setempat yang terdiri dari LINMAS, ketua RT, ketua RW, ibu-ibu PKK dan para generasi muda dari karang taruna, biasanya ibu-ibu PKK menyiapkan hidangan untuk dimakan saat sedang istirahat, dan bapak-bapak serta karang taruna menyiapkan alat-alat seperti kursi, tong sampah, sapu dan lain-lain untuk bersih-bersih setelah acara selesai.

Masa lalu ada pula pertunjukan untuk syukuran atas permintaan individu, seperti kelahiran, khitanan dan kaulan. Panitia yang terlibat, biasanya langsung dikelola oleh yang menyelenggarakan acara.

\begin{abstract}
Partisipan dalam seni Bringbrung
adalah warga masyarakat yang ikut terlibat dalam pertunjukan seni Bringbrung. Masyarakat yang ikut partisipan, cukup beragam usia, mulai anak-anak hingga kakek-kakek dan nenek-nenek.
\end{abstract}

\section{Struktur Pertunjukan Seni Bringbrung}

Struktur pertunjukan seni Bringbrung dibagi menjadi 4 bagian, yaitu pembukaan penyajian lagu-lagu pokok, penyajian lagulagu tambahan dan penutup. Acara tersebut diawali dengan menyusun sesaji, lalu pembacaan do'a-do'a, ucapan terima kasih kepada semua pihak baik yang terlibat maupun yang hanya menonton acara, mulai memainkan alat musik, setelah beberapa lagu dimainkan, dimulailah menyalakan alat ritual berupa dupa dan membakar menyan sambil lagu selanjutnya dimulai, setelah alat ritual habis menjadi abu, akan berhenti sekitar setengah jam untuk beristirahat sambil makan- makanan sesaji yang telah disiapkan, lalu kesenian Bringbrung dimainkan kembali sampai jam 3 shubuh, sampai akhirnya dipenghujung acara dan penutup, selesailah acara tersebut sambil para panitia acara beres-beres panggung. 
Lirik-lirik lagu dalam pertunjukan seni Bringbrung dipercaya bersifat sakral, hal ini terindikasi dari saat kesenian Bringbrung dimainkan, ada fenomena mistis yang selalu terjadi, seperti peristiwa gelas kaca jatuh dengan sendirinya dari meja saat berlangsungnya kesenian Bringbrung, ada yang kesurupan (trance) dan sebagainya.

\section{a. Pembukaan}

Pentas Kesenian Bringbrung diawali pidato dari panitia penyelenggara dengan mengucapkan rasa syukur, karena dapat bertemu dan berkumpul dalam acara dengan pertunjukan seni Bringbrung. Selanjutnya disampaikan ceramah keagamaan yang dilakukan oleh seorang ustadz, materi ceramah terkait dengan peristiwa yang diadakan seperti isra mi'raj, syukuran, muludan dan sebagainya. Sebelum menabuh instrumen acara dimulai dengan tawasul, yaitu rangkaian pembacaan doa-doa dipimpin oleh pimpinan seni Bringbrung atau ustadz yang sengaja diundang oleh penyelenggara acara. Dalam pembacaan do'a, disertakan pula acara ritual seperti ngukus (bakar kemenyan, hio atau cerutu).

Dalam Pertunjukan seni Bringbrung, biasanya penyelenggara menyediakan hidangan untuk semua peserta (tamu undangan, seniman termasuk warga setempat yang ikut berpartisipasi). Hidangan yang tersaji biasanya berupa aneka makanan seperti kukuluban, kue-kue makanan ringan hingga disediakan tumpeng.

Pada masa lalu, selain ngukus, dilakukan juga nyuguh atau menghidangkan sesaji ritual. Semua yang berhubungan dengan sesajen, pada masa kini dianggap memiliki kecenderungan pada hal-hal yang menyimpang dari agama, dikhawatirkan merujuk pada sesuatu yang musrik, atau sesuatu yang mengada-ada. Oleh karena itu, sesaji sebagai sarana ritual seperti rampe, kopi pahit dan kopi manis dan rurujakan sekarang sudah tidak digunakan lagi pada seni Bringbrung.

Semua makanan yang dihidangkan saat pertunjukan Bringbrung, difungsikan sebagai sedekah syukuran terkait dengan peringatan hari-hari besar Islam, masyarakat di Kelurahan Ledeng berdoa agar makanan yang dihidangkan dapat membawa keberkahan bagi semua orang yang mencicipinya.

\section{b. Penyajian Lagu-Lagu Pokok}

Lagu-lagu yang akan dibawakan yaitu lagu yang ada dalam kitab Barzanji. Lirik dalam kitab tersebut dinyanyikan sambil diiringi oleh waditra dari alat musik Bringbrung. Mereka memulainya dari lagu salam 1 sampai lagu salam 3. Salam 1 dimainkan sesuai kebutuhan atau berulangulang, lagu Salam 2 dimainkan sampai selesai dan terakhir lagu Salam 3. Lagu selanjutnya adalah lagu Bisahri 1 sampai Bisahri 3. Pembacaan doa dan ceramah oleh dalang seperti ceramah yang dilakukan oleh seorang ustadz pada acara yang diselenggarakan selanjutnya ditampilkan lagu-lagu yang lainnya. Secara keseluruhan, susunan lagu-lagu pokok pada seni Bringbrung adalah sebagai berikut:

1) Salam 1 sampai salam 3

2) Bisahri 1 sampai bisahri 3

3) Wulidal

4) Ya Rohman

5) Hasolalkos

6) Badatlana

7) Palakam

8) Manmislu

9) Yamao

10) Yasa

11) YaNabi

\section{c. Penyajian Lagu-Lagu Tambahan}

Selain lagu-lagu pokok yang liriknya bersumber dari kitab Barzanji, ada pula yang berupa lagu tambahan yang disebut Jamjami. Lagu Jamjami adalah lagu yang disajikan setelah lagu-lagu pokok dinyanyikan. Berbeda dengan lagulagu pokok, lagu Jamjami biasa disebut lagu yang bersifat hiburan. Adapun isi liriknya berupa larangan, nasehat dan atau patokan hidup manusia. Di dalam penyajiannya, lagu-lagu Jamjami dinyanyikan secara spontan, kadang kala liriknya pun mengacu pada improvisasi penyanyinya. Lagu-lagu yang termasuk Jamjami, motif tabuhnya cenderung sama, tetapi memiliki 
ritmik yang bertempo agak cepat sehingga ideal untuk diisi tarian dalam pementasannya.

Berikut adalah lagu-lagu yang termasuk jamjami atau hiburan:
1) Kikisngelis
2) Banusalam
3) Ayasiuh
4) Isarongket
5) Itunini
6) Iidialon-alon
7) Yu Lailahaileloh
8) Sontengmiring
9) Ii kediyalah
10) Nabi Adamtuan
11) Sadakarinding
12) Ayunambing

Lagu-lagu Jamjami biasanya diiku- ti tarian oleh masyarakat yang menyaksikannya, dibagian inilah banyak masyarakat yang menari mengikuti irama tabuhan terebang, kadangkala sampai tidak sadarkan diri karena kesurupan. Gerakan tarian yang mereka lakukan tidak memiliki koreografi tetap, mereka melakukan tarian secara improvisasi bergantung pada kemampuan menari yang mereka miliki.

Walaupun terjadi kesurupan, mereka tetap menikmati lagu-lagu yang disajikan dalam lagu Jamjami ini. Mereka tidak khawatir dengan terjadinya kesurupan karena ada orang yang ahli dalam menyadarkannya kembali. Dari sekian banyaknya lagu-lagu Jamjami, yang mendatangkan peristiwa kesurupan di antaranya adalah lagu Kikis Ngelis. Berikut ini adalah lagu dan lirik lagu kikis kelis:

\section{KIKIS NGELIS}

\section{Laras:Salendro}

Surupan: 1=Tugu
Gerakan:Sedang
$\|: \quad 0 \quad-(0$
1) $-(1$
2) 1
${ }^{-}\left(5^{-}\left(\begin{array}{ll}0 & 3\end{array}\right)\right)^{-}(3$
1) 3
$\mathrm{Yu}$
lai
la
ah ha ile
loh
Ki kisnge li
is da roja
tin

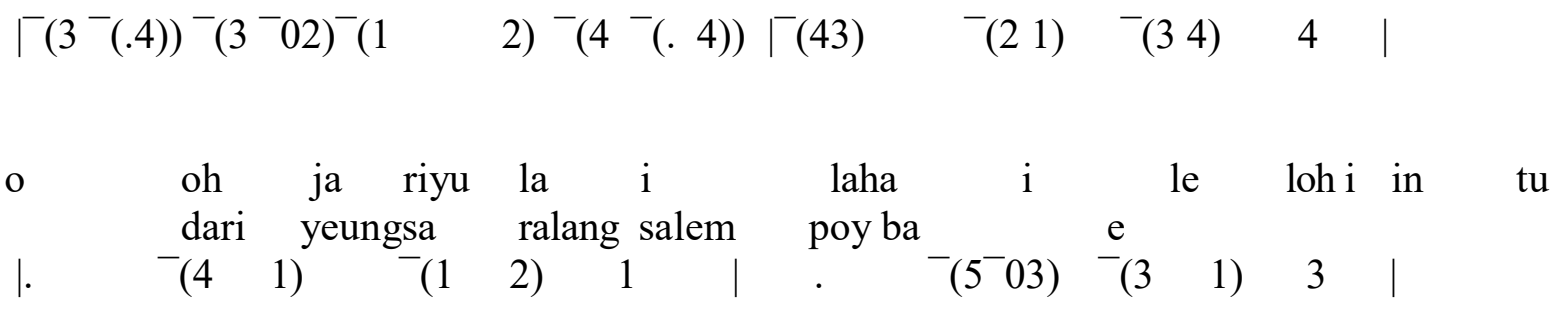

$\begin{array}{lllll}\mathrm{Mu} & \text { hamad } & \mathrm{du} & \text { ro } & \text { sulu loh } \\ \mathrm{tu} & \text { antu lung } & \text { ki } & \text { nulu ngan }\end{array}$




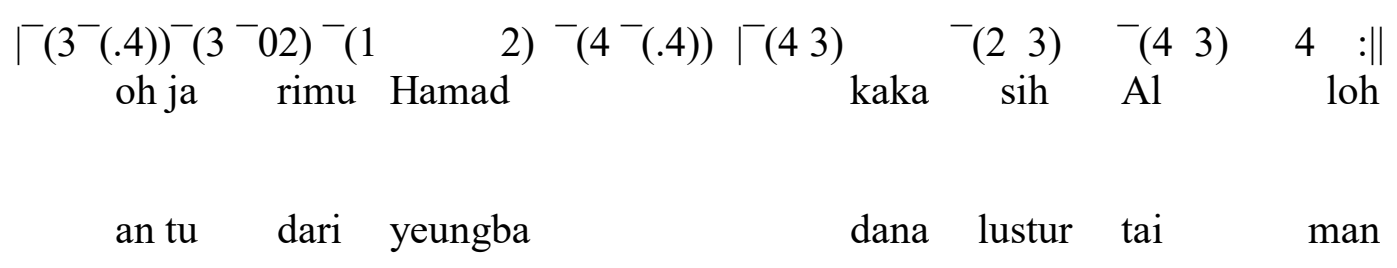

Keterangan:

Lirik lagu dari barisan ke 1 dan

3 dilantunkan dengan cara rampak, namun, lirik lagu dalam barisan ke 2 dan 4 dinyanyikan dengan cara anggana sekar. Lirik lagu Kikis Ngelis seutuhnya sebagai berikut:

Anggana Sekar:

Carita panata istri

Jari parako naon ngaranna Parako naon ngaranna

Jari ngaranna bengker ning iman

Rampak Sekar:

Carita panata istri

Jadi seeng teh naon ngaranna Seeng

teh naon ngaranna

Jari ngaranna tihang ning iman Carita panata istri

Jari hawu the naon ngaranna Hawu teh naon ngaranna

Jari ngaranna dungkuk ning iman

(Sumber: Made Permadi Tesis 2012)

Lirik lagu kikis kelis termasuk sajak kwartet, dengan jumlah baris 4 baris dalam 1 bait. Adapun bahasa yang digunakan terdiri dari 2 bahasa, yaitu bahasa Sunda dan bahasa Jawa.

\section{d. Penutup}

Setelah penyajian seni Bringbrung selesai, biasanya diakhiri dengan ucapan hamdalah oleh semua orang yang hadir. Selain itu karena acara umumnya diselenggarakan dijalan umum, maka setelah pementasan seni Bringbrung, masyarakat yang berpartisipasi diinstruksikan untuk operasi semut atau bersih-bersih jalan karena banyak sampah yang berceceran dari penonton saat kesenian Bringbrung berlangsung.

\section{e. Tempat dan Waktu Pertunjukan}

Lokasi yang digunakan dalam pertunjukkan kesenian tradisional pada umumnya dilaksanakan di tempat terbuka (outdoor), namun ada juga yang di dalam ruangan (indoor), tempat pelaksanaan kesenian Bringbrung tergantung kepada pihak panitia yang mengadakannya, namun biasanya dilakukan di rumah warga di Kelurahan Ledeng yang punya hajat. Waktu pertunjukkan kesenian Bringbrung ini dilaksanakan pada malam hari setelah sembahyang Isya sekitar pukul 20.00 sampai pukul 03.00 pagi.

\section{f. Rias dan Busana Pertunjukan}

Dalam pertunjukkan kesenian tradisional, rias dan busana yang digunakan biasanya bukan pakaian yang mencolok. Para pemain kesenian Bringbrung biasanya memakai baju adat khas Sunda, yaitu baju dan celana pangsi, serta menggunakan ikat kepala dari kain batik.

\section{SIMPULAN}

1. Kesenian Bringbrung adalah satu-satunya kesenian tradisional terebang yang masih bersisa di Kelurahan Ledeng, pelestarinya adalah Abah Enja. Mengingat para senimannya kebanyakan sudah tua, kesenian ini perlu gencar melakukan pewarisan terhadap para generasi mudanya (penerusnya) agar tidak punah.

2. Proses pewarisan budaya yang telah dilakukan dalam seni Bringbrung meliputi sosialisasi, enkulturasi, dan internalisasi. Secara sosialisasi, pewarisan budaya dalam kesenian Bringbrung selain dilakukan terhadap para penduduk masyarakat Ledeng, juga dilakukan terhadap masyarakat luar yang datang ke tempat tersebut. Secara sosialisasi, pewarisan kesenian ini tampak kurang menunjukan hasil yang 
Ricky, Dede, Sriati - Pewarisan Budaya dalam.....

optimal, keragaman penduduk di Kelurahan Ledeng yang mayoritas perantau (anak kost) merupakan faktor penghambat. Secara enkulturasi pewarisan seni Bringbrung dilakukan melalui tahapan-tahapan: membina ketertarikan, ikut terlibat pertunjukan, ikut menabuh dan menyanyi, giat berlatih, dan mampu berimprovisasi dan berinovasi dalam kesenian Bringbrung tersebut. Secara internalisasi pewarisan kesenian Bringbrung dilakukan mulai dari masa kanak- kanak (ikut menyanyi dan menari); masa remaja menjadi panitia dan ikut pertunjukan, ikut berlatih dengan harapan dapat menjadi pemain Bringbrung menggantikan pendahulunya.

3. Media yang diwariskan dalam kesenian Bringbrung meliputi praktek menabuh terebang, menyanyikan lagu-lagu, menari dan pengelolaan keorganisasian.

4. Faktor pendukung dalam pewarisan adalah masyarakat, orang tua, pemerintah, media sosial, seniman dan sanggar seni Bringbrung; sedangkan faktor penghambat meliputi keterbatasan mengenal budaya leluhur, profit seni Bringbrung tidak menjamin kehidupan, derasnya globalisasi yang memarjinalkan seni tradisional.

\section{Saran}

Dalam kesempatan ini, peneliti ingin menyampaikan saran terhadap pewarisan kesenian Bringbrung.

1. Perlu para generasi penerus di Kelurahan Ledeng melakukan pelestarian kesenian Bringbrung, karena sebagai aset budaya bangsa, seni tradisional akan punah bila ditinggalkan penyangganya.

2. Perlu adanya perhatian pemerintah terhadap kesenian tradisional khususnya seni Bringbrung agar senimannya memiliki kelayakan hidup dalam mempertahankan kesenian Bringbrung.

3. Perlu dilakukan pembinaan oleh dinas terkait seni budaya (Disparbud), agar kesenian Bringbrung dapat berkembang sebagai aset bangsa yang diperhitungkan dalam khazanah budaya tradisional tingkat regional, nasional hingga internasional.

\section{DAFTAR PUSTAKA}

Buku

Berry, John. 1999. Psikologi Lintas Budaya. Jakarta: PT Gramedia Pustaka Utama.

Dwi, Komarasari. 2013. Kasenian Bringbrung di Kelurahan Ledeng Kecamatan Cidadap Kota Bandung Pikeun Bahan Pangajaran Maca di SMA Ulikan Struktural-Semiotik. Skripsi pada Universitas Pendidikan Indonesia (UPI). Bandung.

Endraswara, Suwardi. 2003. Metodologi penelitian kebudayaan. Yogyakarta: Universitas Gadjah Mada Press.

Erviana. 2015. Pola Pewarisan Budaya Lokal Dalam Pembetukan KarakterAnak Di Desa Madello, Kecamatan, Balusu, Kabupaten Barru. Skripsi Universitas Hasanuddin. Makasar.

Koentjaraningrat. $1997 . \quad$ Pengantar Antropologi. Jakarta: PT Rineka Cipta.

Kubarsah, Ubun. 1994. Waditra Mengenal Alat-alat kesenian Daerah Jawa Barat. Bandung: CV. Sampurna.

Lexy J. Moleong.1989. Metodologi

Penelitian Kualitatif. Bandung: PT

Remaja Rosdakarya.

Made, Permadi. 2016. Fenomena Kesurupan dalam Kesenian Bringbrung di Kampung Cidadap Hilir Ledeng Kota Bandung. Tesis dari Pasca Sarjana Institut Seni Budaya Indonesia (ISBI). Bandung.

Nia, Emilda. 2016. Laporan Penelitian Pewarisan Seni Tradisi Gondang Buhun sebagai Upaya Pendidikan Karakter Remaja di Kabupaten Pangandaran dari kementerian Riset Teknologi dan Pendidikan Tinggi Institut Seni Budaya Indonesia (ISBI) Bandung.

Oyoh, Komariah. 2001. Tinjauan Deskriptif terhadap seni Bringbrung di Kelurahan Ledeng Kecamatan Cidadap Hilir Kota Bandung. Skripsi dari Sarjana Institut Seni Budaya Indonesia (ISBI) Bandung.

Poerwanto, Hari. 2008. Kebudayaan dan Lingkungan dalam Perspektif Antropologi. Yogyakarta: Pustaka Pelajar. 
Pupun, Nuryanti. 2012. Model Pembelajaran Berlatar Budaya Lokal untuk Meningkatkan Interaksi Pedagogis Tutor dan Siswa. Skripsi dari Universitas Pendidikan Indonesia (UPI). Bandung.

Simanjuntak, Posman. 1997. Berkenalan dengan Antropologi untuk SMU Kelas 3. Jakarta: Erlangga.

Yus, Darusman. 2019. Model Pewarisan Budaya Melalui Pendidikan Informal (Pendidikan Tradisional) Pada Masyarakat Pengrajin Kayu dari jurnal edukasi Universitas Siliwangi Tasikmalaya.

\section{Sumber Internet}

Hadi. 2016. Artikel Kesenian Bringbrung dan Maulid Nabi Muhammad SAW. Peliputan pers Daunjati dari Institut
Seni Budaya Indonesia (ISBI) Bandung:

[http://www.daunjationline.com/2016/1 2/kesenian-bringbrung-dan-maulidnabi.html tahun2016; 7/9/2019: pukul 09.30 WIB]

http://bungasarisebelasbahasasman1ciparay.bl ogspot.com/2013/06/pewarisanbudaya. html 7/9/2019: pukul 09.37 WIB]

https://belajarw.wordpress.com/2012/12/15/se kilas-tentang-seni-terebangbandung/7/9/2019; pukul 09.40 WIB]

https://ilmuseni.com/seni-budaya/kesenianrudat/23/9/2019; $11.25 \mathrm{WIB}]$

http://e-heritage.id/detail/116/17/10/2019; 12.15 WIB]

https://jabar.tribunnews.com/2018/04/01/meng enal-kesenian-genjring-khas-cirebonyang-tinggal-satu-satunya-dicirebon/11/11/2019; 22:07 WIB] 